\title{
Fetal and maternal outcome following expectant management of severe pre-eclampsia remote from term
}

\author{
Deepak A. V. ${ }^{1}$, Reena R. P. ${ }^{1 *}$, Deepa Anirudhan ${ }^{2}$
}

\begin{abstract}
${ }^{1}$ Department of Obstetrics and Gynecology, Government Medical College Hospital, Thrissur, Kerala, India
${ }^{2}$ Department of Pediatrics, Government Medical College Hospital, Thrissur, Kerala, India
\end{abstract}

Received: 21 September 2017

Accepted: 27 October 2017

\author{
*Correspondence: \\ Dr. Reena R. P., \\ E-mail: drreenaravindran@gmail.com
}

Copyright: (c) the author(s), publisher and licensee Medip Academy. This is an open-access article distributed under the terms of the Creative Commons Attribution Non-Commercial License, which permits unrestricted non-commercial use, distribution, and reproduction in any medium, provided the original work is properly cited.

\begin{abstract}
Background: Expectant management of severe preeclampsia, remote from term is often a difficult decision. Maternal and foetal complications may occur while trying to achieve a more favourable perinatal outcome. We wanted to find out the foetal and maternal outcomes of expectant management in these women.

Methods: A prospective cohort study was conducted at Government Medical College, Thrissur, India between May 2013 and April 2015. Women with severe preeclampsia remote from term, who were admitted, managed expectantly and delivered in our hospital during the study period, were recruited. The study subjects were grouped into: Group A (between 28 weeks and 31 weeks 6 days) and Group B (between 32 weeks and 33 weeks 6 days). A structured proforma was used to collect demographic and clinical details. The maternal and foetal outcomes were noted.

Results: There were 4786 deliveries during the study period. Among them 76 (1.58\% of total deliveries) women with severe preeclampsia between 28 weeks and 33-week 6 days gestation on expectant management were included in the study. The mean duration of expectant management was 7.92 days in group A (27 women) and 6.67 days in group B (49 women). Most women required termination of pregnancy for foetal distress $(36.8 \%)$. HELLP syndrome and imminent eclampsia were the maternal complications that occurred. Perinatal loss was significantly more in Group A when compared to Group B.

Conclusions: Expectant management of women with severe preeclampsia remote from term, especially between 32 weeks and 33weeks 6 days, with antenatal corticosteroids and close monitoring, seems a reasonable option in developing countries.
\end{abstract}

Keywords: Early onset severe preeclampsia, Expectant management, Maternal morbidity, Perinatal outcome

\section{INTRODUCTION}

Preeclampsia and complications associated with it remains a leading cause for both maternal and fetal morbidity and mortality in low resource settings.

The incidence of preeclampsia varies between 2 to12 percent of all pregnancies worldwide. Severe preeclampsia, remote from term, occurs in about $25 \%$ of these women. ${ }^{1}$ In developing countries it continues to be a major cause of maternal mortality. Both maternal and fetal morbidity and mortality are reported to be higher in early onset preeclampsia (less than 34 weeks gestation) compared to those with late onset preeclampsia (at or more than 34 weeks gestation). ${ }^{2}$ The perinatal mortality rate also increases proportionate to the severity of preeclampsia. ${ }^{1}$ Women who develop severe preeclampsia are delivered as soon as fetal lung maturity is attained, at or after 34 weeks of gestation or due to worsening of maternal condition. This is often necessary as termination 
of pregnancy remains the definitive treatment for prevention of progressive deterioration due to preeclampsia.

In patients with early onset severe preeclampsia, delivery of the fetus at a very preterm gestation becomes essential because of the potential severe maternal morbidity. This frequently leads to poor perinatal outcomes. The complications of iatrogenic premature birth are more common and with more dire consequences in low resource settings. Expectant management of severe preeclampsia, remote from term, therefore becomes necessary to prevent such dismal events in the fetus. But expectant management may occasionally result in fetal death or fetal asphyxia. ${ }^{3}$

We wanted to study the maternal and perinatal outcome of expectant management in early onset severe preeclampsia, between 28 weeks and 33week 6 days gestation in a public run tertiary care centre.

\section{METHODS}

This was a prospective cohort study conducted in the Department of Obstetrics and Gynaecology, Government Medical College, Thrissur, Kerala between May 2013 and April 2015. We used a census method of data collection after approval of the Institutional Ethics Committee. All women who met the criteria for severe preeclampsia between 28 weeks and 33-week 6 days gestation admitted during the study period were recruited after taking informed consent for expectant management. The study subjects were grouped into: Group A (between 28 weeks and 31 weeks 6 days) and Group B (between 32 weeks and 33 weeks 6 days).

We used the criteria described by Lindheimer et al for diagnosis of severe preeclampsia. ${ }^{4}$ The criteria for diagnosis of severe preeclampsia required one or more of the following : Blood pressure of at least $160 \mathrm{mmHg}$ systolic or $110 \mathrm{mmHg}$ diastolic pressure, oliguria, serum creatinine more than $1.2 \mathrm{mg} / \mathrm{dl}$, cerebral or visual disturbance, altered consciousness, headache, scotomata, or blurred vision, pulmonary oedema or cyanosis, epigastric or right upper quadrant pain, impaired liver function or thrombocytopenia.

A structured proforma was used to collect maternal characteristics and clinical data. The maternal and fetal outcomes were also noted.

Women with complications of severe preeclampsia, requiring immediate termination of pregnancy, as well as those with multiple gestations, major fetal malformations and chronic hypertension were excluded from the study. Those developing any contraindications for expectant management within 24 hours of observation were excluded from the study. Contraindications for expectant management included maternal hemodynamic instability, nonreassuring fetal testing, persistent severe hypertension not responding to medical therapy, persistent headache, visual disturbances, epigastric or right upper quadrant pain, eclampsia, pulmonary oedema, renal failure, worsening of laboratory parameters over 6 to 12 hours, HELLP syndrome and abruptio placentae.

The maternal and fetal conditions of all subjects were evaluated at admission. Intense monitoring of the mother and fetus were then continued. Maternal assessment included evaluation of vital signs, physical examination and periodic clinical and laboratory assessment for signs and symptoms suggestive of deterioration of severe preeclampsia. The fetus was evaluated to exclude signs of distress or compromise.

Laboratory tests performed included serial measurements of complete blood cell count including platelet count, serum creatinine, uric acid and liver enzymes. Urinary protein and urine protein /creatinine ratio was evaluated periodically. Coagulation studies and evaluation for hemolysis (peripheral smear, serum bilirubin and/or lactate dehydrogenase) were considered if the platelet count was $<100,000 / \mathrm{mm}^{3}$, liver enzymes were elevated, or when there were findings suggestive of abruptio placentae. Periodic non-stress test and ultrasound with Doppler flow velocimetry were done to evaluate the fetus and to look for evidence of growth restriction, and/or oligohydramnios.

Blood pressure was controlled with adequate antihypertensive drugs. Parenteral magnesium sulphate was given to those with impending signs of eclampsia. Corticosteroid (Betamethasone) was given to these women to accelerate fetal lung maturity. Pregnancy was prolonged as long as the mother and baby were stable. Termination of pregnancy was done at 34 weeks gestational age or at the onset of any contraindications for expectant management. Maternal complications like eclampsia, pulmonary oedema, renal failure and HELLP syndrome were noted. The mode of delivery was vaginal unless there were obstetric indications for a cesarean section. The details of the baby including weight, Apgar score, admission to the Neonatal Intensive Care Unit (NICU) and neonatal complications like respiratory distress, seizures, intra ventricular hemorrhage (IVH), necrotizing enterocolitis (NEC), fresh stillbirths (FSB) and neonatal deaths (NND) were noted. The babies were followed up till their discharge from the hospital.

A descriptive analysis of the collected data was done using means and percentages. The chi square test was used to compare perinatal loss between the two groups.

\section{RESULTS}

There were 4786 deliveries during the study period of two years. This included 743 (15.5\% of total deliveries) women with Hypertensive disorders of pregnancy (gestational hypertension, preeclampsia and chronic hypertension with or without superimposed 
preeclampsia). Among these women with hypertensive disorders, there were 100 (2\% of total deliveries) women with severe preeclampsia admitted between 28 weeks and 33 week 6 days. 24 (0.5\% of total deliveries) among the one hundred women with severe preeclampsia remote from term, developed contraindications for expectant management within 24 hours of admission. 76 pregnant (1.58\% of total deliveries) women were therefore included in the study and underwent expectant management of severe preeclampsia.

Table 1: Distribution of age and parity among mothers with severe preeclampsia.

\begin{tabular}{|l|l|}
\hline Age & Number $(\%)$ \\
\hline$<20$ years & $2(2.6 \%)$ \\
\hline $21-30$ years & $47(61.8 \%)$ \\
\hline $31-40$ years & $26(34.2 \%)$ \\
\hline $41-50$ years & $1(1.3 \%)$ \\
\hline Parity & $29(38.2 \%)$ \\
\hline Primi & $47(61.8 \%)$ \\
\hline Multi & \\
\hline Gestational age & $27(35.5 \%)$ \\
\hline 28 weeks -31 weeks+6 days (Group A) & $49(64.5 \%)$ \\
\hline 32 weeks -33 weeks+6 days (Group B) & $49(6)$ \\
\hline
\end{tabular}

Most pregnant women in the study group were in the age group of 21-30 years (61.8\%). 47 (61.8\%) women were multiparous. Among the study subjects, 27 (35.5\%) women presented at 28weeks to 31 weeks 6 days of gestation (Group A) and $49(64.5 \%)$ women presented between 32 and 33 week 6 days of gestation (Group B) (Table 1). The mean duration of expectant management in Group A was 7.92 days and in Group B it was 6.67 days.

Table 2: Indications for termination of pregnancy.

\begin{tabular}{|lll|}
\hline $\begin{array}{l}\text { Indication for } \\
\text { termination }\end{array}$ & $\begin{array}{l}\text { Group A } \\
\text { (total no:27) }\end{array}$ & $\begin{array}{l}\text { Group B } \\
\text { (total no:49) }\end{array}$ \\
\hline Completed 34 weeks & $3(11 \%)$ & $8(16.3 \%)$ \\
\hline PPROM & $1(3.7 \%)$ & $3(6.1 \%)$ \\
\hline $\begin{array}{l}\text { Spontaneous preterm } \\
\text { labour }\end{array}$ & $2(7.4 \%)$ & $5(10.2 \%)$ \\
\hline Uncontrolled BP & $2(7.4 \%)$ & $6(12.2 \%)$ \\
\hline $\begin{array}{l}\text { Impending eclampsia } \\
\text { HELLP and partial }\end{array}$ & $4(14.8 \%)$ & $3(6.1 \%)$ \\
\hline HELLP & $4(14.8 \%)$ & $4(8.1 \%)$ \\
\hline $\begin{array}{l}\text { Abruption } \\
\text { Abnormal renal function } \\
\text { test }\end{array}$ & $1(3.7 \%)$ & $1(2 \%)$ \\
\hline $\begin{array}{l}\text { Worsening of Doppler } \\
\text { studies }\end{array}$ & $3(11 \%)$ & $6(12.2 \%)$ \\
\hline Fetal distress (NST/ BPP) & $6(22 \%)$ & $13(26.5 \%)$ \\
\hline
\end{tabular}

$11 \%$ of women in group A and $20 \%$ of women in group $\mathrm{B}$ had their pregnancies prolonged to reach up to or beyond 34 weeks gestational age.
Fetal jeopardy, as evidenced by non-reassuring non-stress test or worsening of Doppler flow studies were the most common indications for termination in both group A and group B. Maternal complications like impending eclampsia and uncontrolled blood pressure were the other conditions necessitating termination of pregnancy (Table 2).

The common complications that developed in the mother in both the groups, during expectant management, were imminent eclampsia (9.2\%), HELLP syndrome and partial HELLP syndrome $(10.5 \%)$. There were no cerebrovascular accidents, eclampsia or maternal deaths (Table 3).

Table 3: Frequency of maternal complications.

\begin{tabular}{|ll|}
\hline Complications & Frequency $(\%)$ \\
\hline Impending eclampsia & $7(9.2 \%)$ \\
\hline HELLP and Partial HELLP & $8(10.5 \%)$ \\
\hline Abruptio placentae & $2(2.6 \%)$ \\
\hline Abnormal renal function test & $1(1.3 \%)$ \\
\hline
\end{tabular}

$44 \%$ subjects in group A and 59\% of subjects in group B were delivered by caesarean section (Table 4).

Table 4: Mode of delivery.

\begin{tabular}{|lll|}
\hline Mode of delivery & $\begin{array}{l}\text { Group A } \\
\text { (total no:27) }\end{array}$ & $\begin{array}{l}\text { Group B } \\
\text { (total no:49) }\end{array}$ \\
\hline Caesarean section & $12(44 \%)$ & $29(59 \%)$ \\
\hline Vaginal delivery & $15(56 \%)$ & $20(41 \%)$ \\
\hline
\end{tabular}

Eleven $(41 \%)$ babies in group A weighed less than $1 \mathrm{Kg}$ at birth while $10 \%$ of babies in group B had a birth weight of less than $1 \mathrm{~kg}$. Most of the babies in group B weighed between 1.1 and $2 \mathrm{~kg}$ at birth $(79.5 \%)$ Table 5 .

Table 5: Birth weight of babies of women with severe preeclampsia between 28 and 34 weeks.

\begin{tabular}{|lll|}
\hline Baby weight & $\begin{array}{l}\text { Group A } \\
(\text { total no:27) }\end{array}$ & $\begin{array}{l}\text { Group B } \\
\text { (total no:49) }\end{array}$ \\
\hline$<1 \mathrm{~kg}$ & $11(41 \%)$ & $5(10.2 \%)$ \\
\hline $1.1-2 \mathrm{~kg}$ & $16(59 \%)$ & $39(79.6 \%)$ \\
\hline $2.1-3 \mathrm{~kg}$ & 0 & $5(10.2 \%)$ \\
\hline
\end{tabular}

$48 \%$ of babies in group A had an APGAR score of less than 7 at 5 minutes, while only $18 \%$ of babies in group B had similar APGAR scores. Most of the babies (70\%) in group A were admitted to NICU and there were two fresh stillbirths (FSB) and seven neonatal deaths (NND) among them. $20 \%$ of babies required NICU admission in group $\mathrm{B}$ and there were two fresh stillbirths and three neonatal deaths. Fetal respiratory distress was the major complication in both groups (Table 6).

There were fourteen (18.4\%) perinatal deaths among these women on expectant management. The perinatal loss (including stillbirths and neonatal deaths) in Group A 
was $33.3 \%$ and in Group B it was $10.2 \%$. This difference was statistically significant $(\mathrm{p}<0.05)$.

Table 6: Perinatal complications.

\begin{tabular}{|lll|}
\hline $\begin{array}{l}\text { Perinatal } \\
\text { complications }\end{array}$ & $\begin{array}{l}\text { Group A } \\
(\text { total no:27) }\end{array}$ & $\begin{array}{l}\text { Group B } \\
\text { (total no:49) }\end{array}$ \\
\hline Low APGAR & $13(48 \%)$ & $9(18 \%)$ \\
\hline NICU admission & $19(70 \%)$ & $10(20.4 \%)$ \\
\hline FSB & $2(7 \%)$ & $2(4 \%)$ \\
\hline NND & $7(26 \%)$ & $3(6 \%)$ \\
\hline Respiratory distress & $8(29.6 \%)$ & $5(10.2 \%)$ \\
\hline Seizure & $3(11 \%)$ & $1(2 \%)$ \\
\hline $\begin{array}{l}\text { Intra ventricular } \\
\text { haemorrhage }\end{array}$ & $2(7 \%)$ & 0 \\
\hline $\begin{array}{l}\text { Necrotising } \\
\text { enterocolitis }\end{array}$ & $1(3.7 \%)$ & 0 \\
\hline
\end{tabular}

\section{DISCUSSION}

Most of the babies (70\% in Group A and 20\% in Group B) required admission to the neonatal intensive care unit as expected, due to their extreme prematurity and /or complications that arose from it. Most of the perinatal deaths occurred in Group A (gestational age of 28 weeks to 31 weeks and 6 days), including two stillbirths and seven neonatal deaths, resulting in a $33.3 \%$ perinatal loss. In Group B there were two stillbirths and three neonatal deaths, resulting in $10.2 \%$ fetal loss in this group. The perinatal loss in Group A compared to Group $B$ was statistically significant $(p<0.05)$. The overall perinatal mortality was $18.4 \%$. The MEXPRE Latin study also showed a high incidence of perinatal loss in women with severe preeclampsia at 28-29 weeks compared to a loss of only $1.9 \%$ in pregnancies 32 weeks and beyond. The chances for fetal survival are better with advanced gestational age at delivery.

Prolongation of pregnancy in women with severe preeclampsia remote from term with close monitoring, corticosteroid therapy for fetal lung maturity, aggressive antihypertensive therapy and prophylactic magnesium sulphate has shown to improve fetal outcomes. Randomized controlled trials in 1994 showed improvement in perinatal outcome with lower incidence of neonatal complications, with no adverse effect on maternal outcome. ${ }^{6}$

Sibai et al suggested that expectant treatment in a select group of women with severe preeclampsia between 24 $0 / 7$ and $326 / 7$ weeks gestation in a safe hospital environment resulted in better neonatal outcomes. ${ }^{7}$ Intense fetal surveillance and early detection of fetal compromise and intervention is essential to achieve this outcome.

Expectant management of pregnant mothers with early onset severe preeclampsia resulted in advanced gestational age at delivery, higher birth weights and reduction in the overall perinatal morbidity, neonatal complications and requirement for ventillatory support in other studies. ${ }^{8,9}$

The most common reason for terminating pregnancy was deterioration of fetal condition in most studies. ${ }^{7}$ In this study too, fetal jeopardy (non-reassuring non-stress test or worsening of Doppler studies) was the most common indication $(36.8 \%)$ for discontinuing expectant management. Close fetal surveillance, early recognition of evidence of fetal distress and timely intervention are important to prevent adverse perinatal events.

Pregnancy could be prolonged by an average of seven days in women who presented with severe preeclampsia remote from term. Expectant management for severe preeclampsia remote from term is a useful mode of management in developing countries with limited neonatal care facilities. Prolongation of pregnancy by an average of 11.6 days was shown to be beneficial in tertiary / academic hospitals in South Africa. ${ }^{10}$ Neonatal survival is directly related to gestational age at delivery and birth weight. ${ }^{11}$ In the present study too perinatal loss was higher in babies less than 32 weeks.

Impending eclampsia, HELLP syndrome and abruptio placentae were the complications that developed requiring immediate termination of pregnancy in women on expectant management in the present study. Serious maternal complications like cerebrovascular accidents, eclampsia or maternal death did not occur. Early onset severe preeclampsia has been associated with severe maternal morbidity including respiratory morbidity, cardiovascular morbidity, renal failure and maternal mortality. $^{2}$

A large multicenter randomized trial, the MEXPRE Latin study which compared prompt delivery to expectant management of severe preeclampsia remote from term did not demonstrate neonatal benefit with prolongation of pregnancy. ${ }^{5}$ Their study suggests that prompt delivery following corticosteroid therapy results in similar neonatal outcomes when pregnancy is prolonged for an additional 10 days. Conservative approach may increase risk of placental abruption, small for gestational age fetuses and may put babies at risk for unclear long-term sequelae. $^{5}$

Expectant management of severe preeclampsia remote from term is therefore a controversial decision. Difficulty arises in balancing potential maternal morbidity of expectant management with iatrogenic premature birth. Intensive maternal and fetal monitoring, corticosteroid therapy, experienced medical personnel, adequate infrastructure and support, with good neonatal care will help to improve outcomes. This was a hospital based study and subjects were followed up only up to their discharge from hospital. The long-term implications of severe preeclampsia on the mothers and the developmental and neurological outcomes of their babies could not be studied. 


\section{CONCLUSION}

Expectant management of women with severe preeclampsia remote from term while awaiting the effect of antenatal corticosteroids and prolonging pregnancy with close monitoring, has shown to be beneficial in the present study. The perinatal outcome was seen to be better in women with severe preeclampsia between 32 weeks and 33 weeks 6 days compared to women at less than 32 weeks. Intensive monitoring of both the maternal and foetal condition is essential to improve neonatal outcome and to avoid adverse events in the mother.

Funding: Institutional Research Committee Government Medical College Thrissur

Conflict of interest: None declared

Ethical approval: The study was approved by the Institutional Ethics Committee

\section{REFERENCES}

1. Ciantar E, Walker JJ. Pre-eclampsia, severe preeclampsia and hemolysis. Elevated liver enzymes and low platelets syndrome: what is new?. Womens Health. 2011;7:555-69.

2. Lisonkova S, Sabr Y, Mayer C, Young C, Skoll A, Joseph KS. Maternal morbidity associated with early-onset and late-onset preeclampsia. Obstet Gynecol. 2014;124:771-81.

3. Churchill D, Duley L, Thornton JG, Jones L. Interventionist versus expectant care for severe preeclampsia between 24 and 34 weeks' gestation. The Cochrane Database of Systematic Reviews. 2013;7:CD003106.

4. Lindheimer MD, Taler SJ, Cunningham FG: Hypertension in pregnancy. J Am Soc Hypertens 2:484:2008b.

5. Gracia VP, Tejada RO, Miñaca CAC, Tellez G, Chon VY, Herrarte E, et al. Expectant management of severe preeclampsia remote from term: the MEXPRE Latin study, a randomized, multicenter clinical trial. Am J Obstet Gynecol 2013;209:425.e18.

6. Sibai BM, Mercer BM, Schiff E, Friedman SA. Aggressive versus expectant management of severe preeclampsia at 28 to 32 weeks' gestation: a randomized controlled trial. Am J Obstet Gynaecol. 1994;171:818-22.

7. Sibai BM, Barton JR. Expectant management of severe preeclampsia remote from term: patient selection, treatment, and delivery indications. Am J Obstet Gynaecol. 2007;196:514.

8. Odendaal HJ, Pattinson RC, Bam R, Grove D, Kotze TJ. Aggressive or expectant management for patients with severe preeclampsia between 28-34 weeks' gestation: a randomized controlled trial. Obstet Gynaecol. 1990;76:1070-5.

9. Sibai BM, Taslimi M, Abdella TN, Brooks TF, Spinnato JA, Anderson GD. Maternal and perinatal outcome of conservative management of severe preeclampsia in mid-trimester. Am J Obstet Gynaecol. 1985;152:32-7.

10. Oettle C, Hall D, Roux A, Grove D. Early onset preeclampsia: expectant management in a secondary hospital in close association with a tertiary care institution. BJOG. 2005;112;84-8.

11. Marozio L, Gibbone E, Polarolo G, Carbonara C, Berchialla P. Expectant management of severe preeclampsia remote from term: a hospital-based survey. Ann Reprod Med Treat. 206;1(1):1005.

Cite this article as: Deepak AV, Reena RP, Anirudhan D. Fetal and maternal outcome following expectant management of severe pre-eclampsia remote from term. Int J Reprod Contracept Obstet Gynecol 2017;6:5420-4. 